\title{
Die Bestimmung der Glucosekonzentration in 20 Mikroliter Kapillarblut, Liquor und Urin nach der Hexokinasemethode mit dem Endpunktautomaten 5030 (Eppendorf)
}

\author{
Von R. Haeckel und Hella Haeckel \\ Institut für Klinische Chemie (Geschüftsfübr. Direktor: Prof. Dr. Dr. J. Büttner) Medizinische Hocbscbule Hannover
}

(Eingegangen am 30. Mai 1972)

\begin{abstract}
Die Glucosckonzentration kann nach der Hexokinasemethode mit Hilfe des Eppendorf Endpunktautomaten 5030 in Blut, Urin und Liquor mit austeichender Zuverlässigkeit bestimmt werden. Die Dosierung der Proben kann vom Stationspersonal mit heparinisierten Glaskapillaren $(20 \mu \mathrm{l})$ durchgeführt werden. Diese können in Eppendorf-Reaktionsgefäßen, die cine entsprechende Vorlage enthalten, per Rohrpost in das Laboratorium geschickt werden.

Bei Urin ist das Mitführen eines Probenleerwertes erforderlich. Soll dieser bei Blutproben vermieden werden, muß ein Enteiweißungsmittel verwendet werden, das eine für Messungen im nahen UV-Bereich genügende Klärung des Überstandes erzielt. Diese Bedingung wird von $\mathrm{Zn}(\mathrm{OH})_{2}$, nicht jedoch von Perchlorsäure erfüllt.

Obwohl der prozentuale Verschleppungskoeffizient bei $0,9 \%$ liegt, muß bei extremen Konzentrationsdifferenzen aufeinanderfolgender Proben innerhalb des linearen Meßbereiches eine mögliche Verfälschung der Ergebnisse durch Verschlcppungscffekte beachtet werden. Ebenso kann es bei stark lipämischen Proben zu einer erheblichen Verfälschung des Mcßwertes kommen. Bei einer Triglyceridkonzentration von $12 \mathrm{mmol} / \mathrm{l}$ wird der Überstand durch $\mathrm{Zn}(\mathrm{OH})_{2}$ noch ausreichend geklärt.
\end{abstract}

\section{The determination of glucose by the hexokinase metbod in 20 microlitre samples of capillary blood, cerebrospinal fluid, or urine, using the Eppendorf automatic end point apparatus 5030}

The glucose concentration of blood, urine and cerebrospinal fluid can be determined with satisfactory reliability using the Eppendorf automatic end point apparatus 5030 . Samples can be taken by ward personel with heparinized glass capillaries $(20 \mu \mathrm{l})$. These can be sent by tube post to the laboratory in Eppendorf reaction vessels.

A sample blank is required for urine. In the absence of a sample blank for blood, a deproteinizing agent must be used, which gives clearing of the supernatant for measurements in the near $\mathrm{UV} ; \mathrm{Zn}(\mathrm{OH})_{2}$ is suitable, but not perchloric acid.

Although the percent carry over coefficient is $0.9 \%$, extreme concentration differences within the linear measurement range between neighbouring samples in serial determinations can cause inaccurate results due to carry over. Highly lipaemic samples can also lead to considerable inaccuracy; at a triglyceride concentration of $12 \mathrm{mmol} / \mathrm{l}$, the supernatant is still sufficiently cleared by $\mathrm{Zn}(\mathrm{OH})_{2}$.

Die Glucosekonzentration kann mit Hilfe der gekoppelten Hexokinase/Glucose-6-phosphat-dehydrogenase-Reaktion sowohl im Blut $(1,2)$ als auch im Urin $(3,4)$ zuverlässig bei $340 \mathrm{~nm}$ bestimmt werden. Die Senkung der Reagenzienkosten sowie eine weitgehende Mechanisierung haben $\mathrm{zu}$ einer breiten Anwendung dieser Methode in der klinischen Routinediagnostik geführt.

Im folgenden wird über die Zuverlässigkeit dieser Glucosebestimmung mit dem Endpunktautomaten der Firma Eppendorf-Gerätebau, einem kombiniert-diskreten System (5) berichtet. Als ein besonderes Problem hat sich dabei die Probenvorbereitung erwiesen. Soll das Mitführen eines Leerwertes vermieden werden, müssen aus den Proben alle Substanzen entfernt werden, die bei $340 \mathrm{~nm}$ Licht absorbieren.

Die im sichtbaren Wellenlängenbereich absorbierenden Stoffe werden mit den üblichen Enteiweißungsmitteln weitgehend abgetrennt. Nach früheren Mitteilungen verschiedener Autoren $(6-10)$ werden bei Blutproben durch Perchlorsäure und Trichloressigsäure einige Proteine (Seromucoid, $\alpha_{1}$-Glycoproteid, Haptoglobin) nicht ausgefällt. Daher haben wir untersucht, ob der Úberstand bei den gebräuchlichen Enteiweißungsverfahren noch Substanzen enthält, die im nahen UV-Bereich $(334-366 \mathrm{~nm})$ Licht absorbieren und somit das Ergebnis verfälschen können.

Die Proben werden nach dem von HILGer et al. (11) beschriebenen Verfahren mit heparinisierten Glaskapillaren dosiert.

\section{Material und Methoden}

Die Reaktionslösungen für die Bestimmung der Glucose wurden aus der Testkombination Nr. 15931, für die der Triglyceride aus der Testkombination Nr. 15989 von Boehringer Mannheim entnommen. Reduziertes Glutathion wurde ebenfalls von Boehringer Mannheim bezogen, 2,4-Dinitrophenol von Serva Heidelberg, Serum-Albumin vom Rind (trocken, reinst) von den Behringwerken (Marburg), Maleimid von Dr. Th. Schuchard (München), Lerolat N 100 von Bayer AG (Leverkusen), Monitrol von Merz und Dade (München), Keto-Diastix Teststreifen von Miles GmbH (Frankfurt), alle anderen Chemikalien p. a. von der E. Merck AG (Darmstadt) und heparinisierte Glaskapillaren von der Firma Vogel (Gießen).

\section{Geräte}

Eppendorf Gerätebau (Hamburg): Zentrifuge 5411 (4 min), Zentrifuge 3200 (2 min), Rotationsmischer 3300, Reagenzdosierer 5231, Endpunktautomat 5030, Reaktionsgefäße 3810.

Spektren zwischen $230 \mathrm{~nm}$ und $700 \mathrm{~nm}$ wurden in Quarzküvetten mit eincm DMR 21 der Firma C. Zeiss (Oberkochen) aufgezeichnet. 
Lösungen

1. Zinksulfat (Merck, Best. Nr. 8881) $6 \mathrm{~g}$ ad $1000 \mathrm{ml} \mathrm{H}_{2} \mathrm{O}$.

2. Bariumhydroxid, (Merck, Best. Nr. 1737) $16 \mathrm{~g}$ ad $1000 \mathrm{ml} \mathrm{H}_{2} \mathrm{O}$.

Diese Lösung wird einmal wöchentlich angesetzt und anschließend sofort filtriert (Blauband-Filter Nr. 5893, Schleicher \& Schüll).

3. Reduziertes Glutathion, $768 \mathrm{mg}$ ad $10 \mathrm{ml} \mathrm{H}_{2} \mathrm{O}(0,25 \mathrm{~mol} / 1)$. Im Kühlschrank mindestens 4 Wochen haltbar.

4. Reaktionslösung (Lösung 1 bis 4 aus dex Biochemica Testkombination)

\begin{tabular}{|c|c|c|}
\hline Lösung 1 & $95 \mathrm{ml}$, & $\begin{array}{l}\text { Endkonzentration im Testansatz: } \\
\text { Triäthanolamin-Puffer } 226 \mathrm{mmol} / \mathrm{l} \text {, } \\
\mathrm{MgSO}_{4} 3 \mathrm{mmol} / \mathrm{l}, \mathrm{pH}=7,5\end{array}$ \\
\hline & & NADP $0,38 \mathrm{mmol} / \mathrm{l}$ \\
\hline & $4 \mathrm{ml}$, & ATP $0,51 \mathrm{mmol} / 1$ \\
\hline $\begin{array}{l}\text { Lösung } 4 \\
\text { (Enzymsuspension) }\end{array}$ & $1 \mathrm{ml}$, & $\begin{array}{l}\text { Hexokinase } 7,9 \mathrm{mg} / 1 \text {, Glucose- } 6 \text { - } \\
\text { phosphat-dehydrogenase } 7,9 \mathrm{mg} / 1\end{array}$ \\
\hline & & $80 \mu \mathrm{l}$ \\
\hline Gluta & $5 \mathrm{ml}$, & $9,91 \mathrm{mmol} / \mathrm{l}$ \\
\hline
\end{tabular}

Die fertige Reaktionslösung hält sich bei $4^{\circ} \mathrm{C}$ mindestens $24 \mathrm{~h}$, bei Raumtemperatur $\left(22^{\circ} \mathrm{C}\right)$ mindestens $7 \mathrm{~h}$.

5. Lerolatlösung, $1 \mathrm{ml}$ Lerolat ad $10 \mathrm{ml} \mathrm{H}_{2} \mathrm{O}$.

6. Leerwertlösung (Lösung 1 und 2 aus der Biochemica Testkombination)

$100 \mathrm{ml}$, Triäthanolamin-Puffer $226 \mathrm{mmol} / \mathrm{l}$, $\mathrm{MgSO}_{4} 3 \mathrm{mmol} / \mathrm{l}, \mathrm{pH}=7,5$

Lösung 2

Glutathion (s. o.) $\quad 5 \mathrm{ml}, 9,91 \mathrm{mmol} / \mathrm{l}$

Lerolatlösung $\quad 0,1 \mathrm{ml} 80 \mu \mathrm{l} / \mathrm{l}$

7. Dinitrophenol-Lösung, $60 \mathrm{mg}$ ad $1000 \mathrm{ml} \mathrm{H}_{2} \mathrm{O}$. In einer dunklen Flasche gut verschlossen mehrere Monate haltbar.

8. Glucose-Standardlösung, $10 \mathrm{mmol} / 1$ : $180,16 \mathrm{mg}$ getrocknete Glucose (Merck, Best. Nr. 8337), 100 mg Natriumazid (Merck, Best. Nr. 6688) und $\mathrm{H}_{2} \mathrm{O}$ ad $100 \mathrm{ml}$.

9. Die Präzision der Konzentrationsbestimmung von Harnglucose wurde mit einer Kontrollprobe überprüft, die folgendermaßen angesetzt wurde: der Inhalt einer Flasche Kontrollurin (Hyland, Charge Nr. 0402 MOOBA 1) wurde in $100 \mathrm{ml}$ Natriumazidlösung $(1 \mathrm{~g} / \mathrm{I})$ aufgenommen, in Reaktionsgefäße abgefüllt und bei $-20^{\circ} \mathrm{C}$ eingefroren. Jeden Montag wurde der Wochenbedarf (1 Reaktionsgefäß) aufgetaut und im Kühlschrank aufbewahrt.

10. Alkoholische Zinksulfatlösung, $2,4 \mathrm{~g} \mathrm{ZnSO}_{4} \cdot 7 \mathrm{H}_{2} \mathrm{O}+200 \mathrm{ml}$ Äthylalkohol (absolut) mit $\mathrm{H}_{2} \mathrm{O}$ ad $1000 \mathrm{ml}$ auffüllen.

11. Maleimidlösung: $10 \mathrm{mg} / 100 \mathrm{ml}$

\section{Enteiveißung mit Zinkbydroxid}

In ein Reaktionsgefäß nacheinander dosieren:

$500 \mu \mathrm{ZnSO}_{4}$ (Reagenzdosierer)

$20 \mu \mathrm{l}$ Probe (Glaskapillare oder Eppendorf Pipette)

Reaktionsgefäß verschließen. Mindestens $5 \mathrm{mal}$ kräftig hin- und herschütteln. Die Probe kann jetzt $24 \mathrm{~h}$ aufbewahrt werden. Unmittelbar vor der Analyse:

$100 \mu \mathrm{l} \mathrm{Ba}(\mathrm{OH})_{2}$ (Reagenzdosierer)

30 s schütteln (Rotationsmischer). Zentrifugieren.

Die mit $\mathrm{ZnSO}_{4}$-Lösungen vorbereiteten Reaktionsgefäße können (fest verschlossen) bis zu 2 Monate bei Raumtemperatur aufbewahrt werden. Während dieser Zeit ist die Volumenabnahme infolge von Verdunstung kleiner als $1 \%$. Die Glaskapillare verbleibt nach Ausschütteln der Probe im Reaktionsgefäß. Wenn nicht geschüttelt wurde, kann dies vor der Zentrifugation nachgeholt werden. Es sollte jedoch immer darauf geachtet werden, daB der Kapillareninhalt nach der Zentrifugation klar ist (Transparente Reaktionsgefäße, z. B. aus Polypropylen verwenden!).

Die Glucosekonzentration bleibt in der $\mathrm{ZnSO}_{4}$-Vorlage mindestens $24 \mathrm{~h}$ konstant. Danach kommt es bei manchen Kapillarblutproben zu einem allmählichen Abbau dieses Zuckers. Soll das 'Untersuchungsmaterial über einen längeren Zeitraum in der Vorlage aufbewahrt werden, kann durch Zusatz von Maleimid (10 mg/
$100 \mathrm{ml}$ ) der Glucoseabfall (12) über mindestens $72 \mathrm{~h}$ verzögert werden.

$\mathrm{Die} \mathrm{Ba}(\mathrm{OH})_{2}$-Lösung wird mit einem Reagenzdosierer in die Vorlage pipettiert. Mit Hilfe einer Stahlkanüle (Nr. 1, Außendurchmesser $0,9 \mathrm{~mm}$ ), die mit einem Entnahmegriffstück (Eppendorf Gerätebau, Bestell Nr. 523081) gehalten und über ein Schlauchsystem mit dem Dosierer verbunden ist, wird der Deckel der Reaktionsgefäße durchstochen. Dadurch entfällt das Offnen und Schließen der Reaktionsgefäße. Vor jeder Serie muß das Schlauchsystem entweder gewechselt oder mit $0,1 \mathrm{~mol} / 1 \mathrm{HCl}$ durchgespült werden.

Um den Grad der Enteiweißung festzustellen, wurde der Uberstand manuell in Reaktionsgefäßen aufbereitet und direkt in der Durchflußküvette des Endpunktautomaten bei $334 \mathrm{~nm}$ gegen den entsprechenden Reagenzienleerwert gemessen. Rechner und Drucker erfassen die gemessenen Extinktionen auf 3 Dezimalstellen.

\section{Enteivveißung mit Perchlorsäure}

Die Proben wurden mit heparinisierten Glaskapillaren in Reaktionsgefäße mit $500 \mu \mathrm{l}$ Maleimidlösung (s. o.) dosiert. Nach Zugabe von $100 \mu \mathrm{l}$ Perchlorsäure $(1,98 \mathrm{~mol} / \mathrm{l})$ wurde kutz umgeschüttelt und nach $5 \mathrm{~min}$ zentrifugiert. $50 \mu \mathrm{l}$ Überstand wurden im Endpunktautomaten mit $500 \mu \mathrm{l}$ Reaktions- bzw. Leerwertlösung versetzt und auf Glucose mit dem Leerwertverfahren (Bilirubin-Programmstecker) analysiert. Dex Drucker wurde so eingestellt, daß der Probenleerwert entweder ausgedruckt (Tab. 1) oder vom Analysenwert (Abb. 5) abgezogen wurde.

\section{Reaktionsansatz}

In ein Reaktionsgefäß mit Probe-Reagenzdosierer einfüllen: $100 \mu \mathrm{l}$ Uberstand aus der $\mathrm{ZnSO}_{4} / \mathrm{Ba}(\mathrm{OH})_{2}$-Fällung $500 \mu \mathrm{l}$ Reaktionslösung

Mischen. Bei Raumtemperatur $20 \mathrm{~min}$ inkubieren. Danach photometrische Messung gegen einen Leerwert (100 $\mu 1$ $\mathrm{H}_{2} \mathrm{O}+500 \mu \mathrm{l}$ Reaktionslösung) bei $334 \mathrm{~nm}$.

Der Analysenautomat wird nach Vorschrift der Herstellerfirma bedient (BZ-Programmstecker) und, wenn ein Probenleerwett erforderlich ist, der Bilirubin-Progtammstecker verwendet. Die Einstellung der Probenentnabmenadel erfolgt so, daß diese bis $1 \mathrm{~cm}$ oberhalb der Probentischoberfläche in den Uberstand eintaucht. Die Proben werden nach dem in Abbildung 1 dargestellten Schema in die Kette eingesetzt. Diese Probenfolge einer Serie besteht aus einem Anfangssegment A (Kontrolle von Präzision und Standarddrift), sich je nach Bedarf mehrfach wiederholenden Zwischensegmenten $B_{1,2} \ldots n$ und einem Endsegment $C$. Für Routinebestimmungen kann dieses Schema vereinfacht werden.

Den Anfang einer Serie bilden 3 Gefäße mit einer Farbstofflösung (2,4-Dinitrophenol), um einen eventuellen apparativen Fehler von einer Störung der chemischen Reaktion rasch differenzieren zu

\section{Tab. 1}

Der durch die Enteiweißung mit Perchlorsäure entstehende Fehler bei der Glucosebestimmung

\begin{tabular}{|c|c|c|}
\hline Probenmaterial & $\begin{array}{c}\text { Probenleerwert } \\
\Delta \mathrm{E}_{3 \mathrm{~s} \Delta \mathrm{m}} \\
\overline{\mathbf{x}} \pm \mathrm{s}(\mathrm{n}) \\
\text { (Extrembereich) }\end{array}$ & $\begin{array}{l}\text { Durchschnittlicher } \\
\text { Fehler bezogen auf } \\
\text { eine theoretische } \\
\text { Glucosekonzentrâtion } \\
\text { von. } 5 \mathrm{mmol} / 1^{*} \text { ) }\end{array}$ \\
\hline $\begin{array}{l}\text { Kapillarblut } \\
\text { (Mensch) }\end{array}$ & $\begin{array}{l}0,007 \pm 0,005 \quad(171) \\
(0,001 \leq 0,016)\end{array}$ & $\begin{array}{c}8 \% \\
(1-18 \%)\end{array}$ \\
\hline $\begin{array}{l}\text { Kapillarblut } \\
\text { (Meerschweinchen) }\end{array}$ & $\begin{array}{c}0,010 \pm 0,004 \\
(0,002-0,021)\end{array}$ & $\begin{array}{c}11 \% \\
(2-24 \%)\end{array}$ \\
\hline Moni-Trol I & $\begin{array}{c}0,002 \pm 0,001 \\
(0,000-0,003)\end{array}$ & $\begin{array}{c}2 \% \\
(0-3 \%)\end{array}$ \\
\hline Liquor & $\begin{array}{c}0,002 \pm 0,002 \\
(0,000 \pm 0,005)\end{array}$ & $\begin{array}{c}2 \% \\
(0-6 \%)\end{array}$ \\
\hline
\end{tabular}

*) Eine wäßrige Glucoselösung von $5 \mathrm{mmol} / \mathrm{l}$, die wie eine Probe behandelt wird, führt $z u$ einer Extinktionsdifferenz von $\Delta \mathrm{E}=0,088$. 


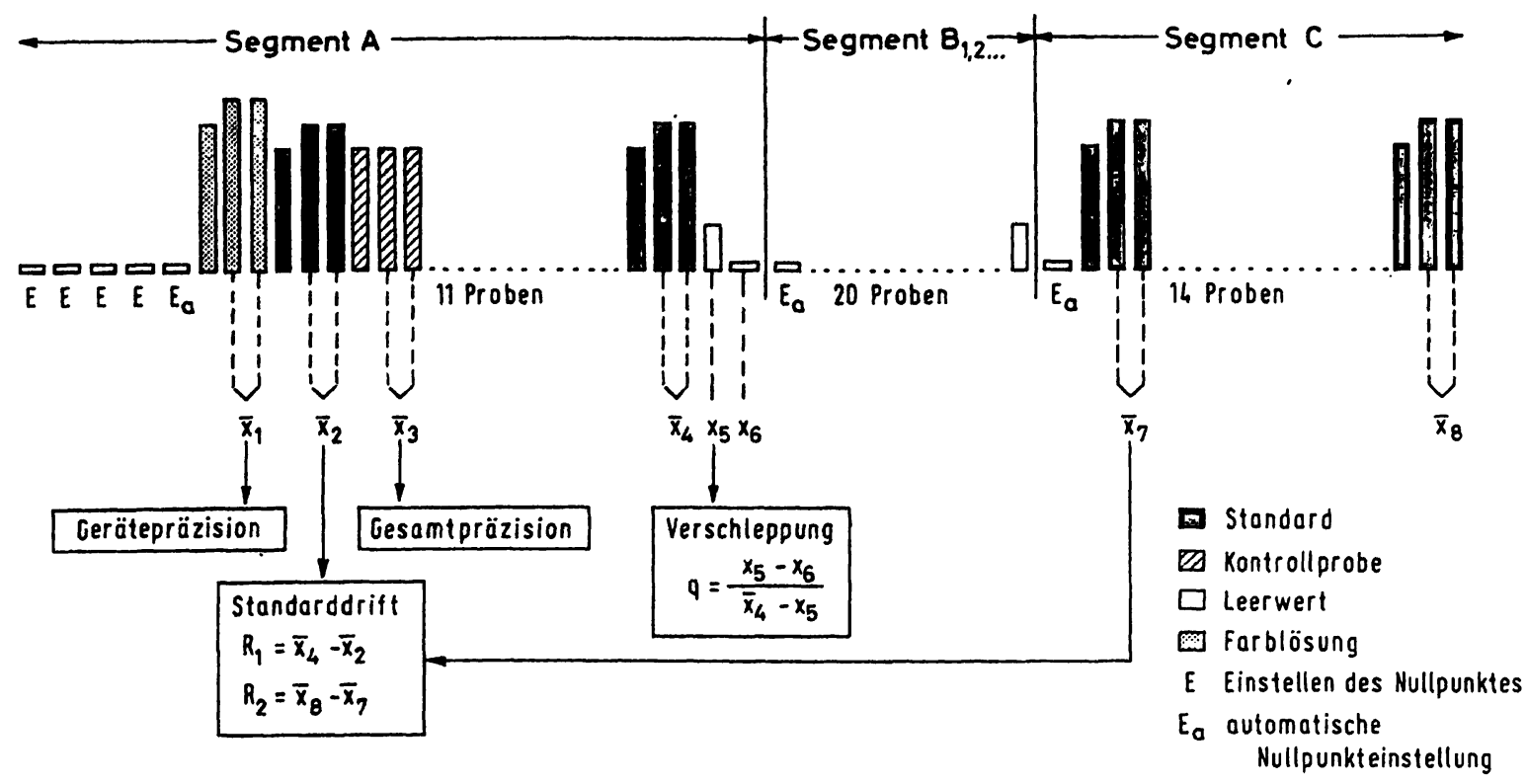

Abb. 1

Probenfolge bei der Glucosebestimmung (ohne Probenleerwert) mit dem Endpunktautomaten 5030

können. Verschleppung und methodische Gesamtpräzision (Kontrollprobe) werden im Anfangssegment der Serie überprüft. Eine Kontrolle der Leerwertdrift erübrigt sich, da in einem Vorversuch über 20 Tage geklärt wurde, daß diese gleich groß wie die Standarddrift ist.

\section{Enteiweißung von Urinproben}

Die Proteine werden im Urin durch $\mathrm{ZnSO}_{4}$ bercits ausreichend gefällt. Die Zugabe von $\left(\mathrm{Ba}(\mathrm{OH})_{2}\right.$ kann daher entfallen. Verdünnung und Enteiweißung lassen sich somit gemeinsam mit 2 Pipettierungen durchführen. Mit Keto-Diastix wird geprüft, ob im Verhältnis 1:11 (50 $\mu \mathrm{l}$ Urin $+500 \mu \mathrm{l} \mathrm{ZnSO}_{4}$, bis zu einer Glucosekonzentration von $20 \mathrm{mmol} / \mathrm{l})$ oder $1: 251(40 \mu \mathrm{l}$ Urin $+10 \mathrm{ml}$ $\mathrm{ZnSO}_{4}$, bis $\left.456 \mathrm{mmol} / \mathrm{l}\right)$ mit $\mathrm{ZnSO}_{4}(6 \mathrm{~g} / 1)$ verdünnt werden muß.

\section{Wiederfindungsversucb}

$500 \mu \mathrm{l}$ Urin, Serum oder heparinisierte Blutproben wurden mit $100 \mu 1 \mathrm{H}_{2} \mathrm{O}$ (c) , bzw. mit $100 \mu \mathrm{l}$ Glucoselösung (20 oder $50 \mathrm{mmol} /$ $1 ; \mathrm{c}_{2}$ ) versetzt und danach wie beschrieben mit $\mathrm{ZnSO}_{4} / \mathrm{Ba}(\mathrm{OH})_{2}$ enteiweißt. Im Uberstand wurde die Glucose bestimmt. Die wiedergefundene Glucosemenge errechnet sich aus $c_{2}-c_{1}$.

Die Bestimmung der Triglyceride erfolgte nach EgGSTEIN und KREUTz (13), die der Cholesterinkonzentration nach Levine und ZAK (14) mit dem AutoAnalyzer.

\section{Ergebnisse \\ Probenvorbereitung}

HILGER et al. (11) beschrieben ein Verfahren, bei dem die Kapillarblutprobe auf den Stationen vom Pflegepersonal entnommen und per Rohrpost in das Labor verschickt werden kann. Dabei wird die Probe mit einer heparinisierten Glaskapillare in ein Eppendorf-Reaktionsgefäß dosiert, das im Laboratorium vorher mit $500 \mu$ l Fluoridlösung gefüllt wurde. Die Enteiweißung erfolgt später durch Zugabe von $100 \mu 1$ Perchlorsäure $(1,98 \mathrm{~mol} / \mathrm{l})$.

Bei diesem Vorgehen fällt auf, daß im sauren Überstand Substanzen zurückbleiben, die bei $340 \mathrm{~nm}$ mit einem Maximum bei $390 \mathrm{~nm}$ absorbieren. Dadurch entsteht ein positiver Fehler, wenn der Überstand bei der Glucosebestimmung in Kapillarblutproben direkt in das enzymhaltige Reaktionsgemisch eingesetzt wird. Ein zweites Maximum wird bei $257 \mathrm{~nm}$ beobachtet, das vermutlich durch Nucleotide bedingt wird. Diese interferieren jedoch nicht mit der Extinktionsmessung zwischen 334 und $366 \mathrm{~nm}$. Auch wenn die Säure erst vorgelegt oder konzentrierter verwendet wird, kommt es nicht zu einer vollständigen Klärung des Überstandes, deren Grad von der Zeit zwischen der Perchlorsâurezugabe und der Zentrifugation abhängt. Es muß mindestens $1 \mathrm{~min}$ bei Raumtemperatur inkubiert werden.

Bei einer Glucosekonzentration von $5 \mathrm{mmol} / \mathrm{l}$ errechnet sich der durch die Enteiweißung mit Perchlorsäure in Kapillarblut zu erwartende Fehler auf durchschnittlich $8 \%$ (Tab. 1). Bei einem geringeren Glucosegehalt würde der Fehler größer, bei einer höheren Glucosekonzentration entsprechend kleiner sein.

Erhöht man die Probenmenge (z. B. auf $100 \mu \mathrm{l}$ ) bei konstantem Vorlagevolumen $(500 \mu \mathrm{l})$, so nimmt die im Úberstand verbleibende, absorbierende Substanz nur gering zu (Abb. 2), so daß deren Verhältnis zu durch Glucose gebildetem NADPH günstiger wird.

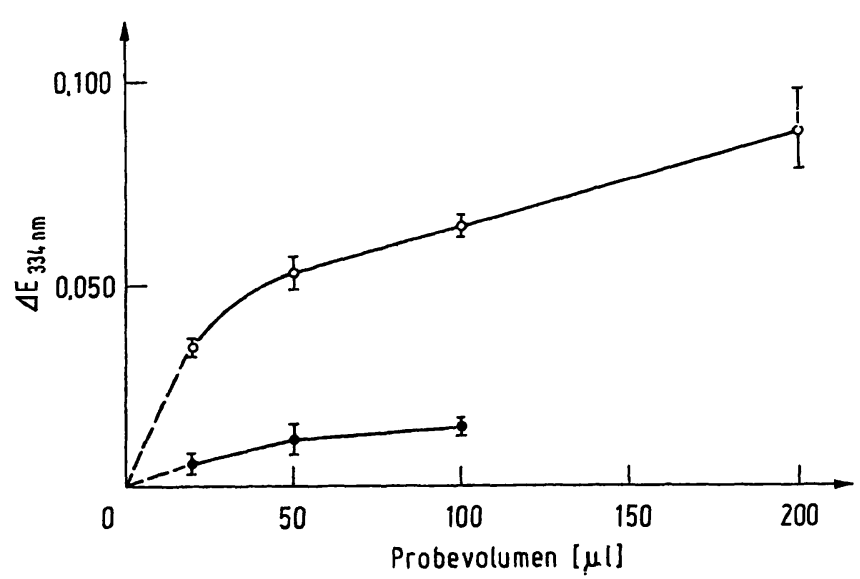

Abb. 2

Der Einfluß des Probevolumens (heparinisiertes Venenblut) auf den Extinktionswert des Uberstandes nach der. Enteiweißung mit Perchlorsäure (0ـ, $500 \mu \mathrm{l}$ Perchlorsäure, $0,33 \mathrm{~mol} / \mathrm{l})$ und $\mathrm{ZnSO}$ al $\mathrm{Ba}(\mathrm{OH}),(\theta-\theta) \cdot \overline{\mathrm{x}} \pm \mathrm{s}(\hat{\mathrm{n}}=5)$ 
Tab. 2

Die Extinktionsmessung des Überstandes bei der Enteiweißung von Kapillarblut und Lösungen unterschiedlicher Proteinkonzentration mit $\mathrm{ZnSO}$, und $\mathrm{Ba}(\mathrm{OH})$, gegen bidest. Wasser

\begin{tabular}{llrr}
\hline & \multicolumn{4}{c}{$\Delta \mathrm{E}_{\mathbf{3} 3 \mathrm{~nm}}$} & \\
& $\overline{\mathrm{x}}$ & $\mathrm{s}$ & $\mathrm{n}$ \\
\hline Kapillarblut & 0,003 & 0,002 & 20 \\
Monitrol I (Protein: $69 \mathrm{~g} / \mathrm{l})$ & 0,004 & 0,001 & 5 \\
Monitrol I*) (Protein: $138 \mathrm{~g} / \mathrm{l})$ & 0,004 & 0,001 & 5 \\
Albuminlösung (100 g/l) & 0,003 & 0,001 & 5 \\
Albuminlösung (200 g/l) & 0,006 & 0,002 & 5 \\
\hline
\end{tabular}

*) in der halben Menge Lösungsmittel aufgenommen.

Eine andere Möglichkeit der Deproteinisierung bietet das auf SomogyI (15-17) zurückgehende Verfahren mit $\mathrm{ZnSO}_{4}$ und $\mathrm{Ba}(\mathrm{OH})_{2}$, bei dem das Volumenverhältnis von Probe zum Enteiweißungsmittel nicht kritisch ist (Abb. 2). Die direkte Messung des Überstandes bei $334 \mathrm{~nm}$ gegen Wasser ergibt auch hier eine geringe Extinktionsdifferenz, die bei Serum und Kapillarblut in der oberen Hälfte des Uberstandes jedoch stets unter 0,010 liegt und daher vernachlässigt werden kann (Tab. 2). Bei höherer Proteinkonzentration wird mit diesem Verfahren ebenfalls noch ausreichend enteiweißt (Tab. 2). $\mathrm{Zu}$ beachten ist, daß aus der oberen Hälfte des Úberstandes abpipettiert wird. Beim Stehenlassen des Überstandes von Blut- und Serumproben kommt es nicht zu einem geringen Ansteigen der Glucosekonzentration wie nach der Behandlung mit Perchlorsäure (Hydrolytische Spaltung von Polysacchariden).

Wird die mit Blut gefüllte Glaskapillare in einer alkoholischen Zinksulfat-Lösung (Tab. 3) ausgeschüttelt, kann sofort abgeschleudert werden. Auch ohne weitere Zugabe von OH-Ionen liegt bei Kapillarblut und Serumproben die direkt gegen $\mathrm{H}_{2} \mathrm{O}$ gemessene Extinktionsdifferenz des Überstandes bei $334 \mathrm{~nm}$ unter 0,010. Diese Vorlage verdunstet aber bei Raumtemperatur in fest verschlossenen Reaktionsgefäßen mit einer Geschwindigkeit von etwa $1 \mu \mathrm{l} / \mathrm{h}$ während der ersten Stunden.

Wolframat-, Sulfosalicylat-, Uranylacetat- und Pikrationen eignen sich wegen ihrer hohen Eigenabsorption bei $340 \mathrm{~nm}$ nicht als Enteiweißungsmittel für die Hexokinasemethode.

\section{Reaktionskinetik}

Die Registrierung des Reaktionsablaufes zeigt, daß die NADPH-Bildung im Überstand aus der $\mathrm{ZnSO}_{4}$ $\mathrm{Ba}(\mathrm{OH})_{2}-$ Fällung gehemmt ist. Dieser Effekt wird durch Zusatz von reduziertem Glutathion (Abb. 3) aufgehoben. Die Reaktion kommt bei Raumtemperatur und einet Glucosekonzentration von $10 \mathrm{mmol} / \mathrm{l}$ nach etwa 10 min zum Stillstand; auch mit Kapillarblut wurde kein „Schleich“" beobachtet. Enthält die Reaktionslösung Glutathion, müssen wäßr. Glucoselösungen wie Proben mit $\mathrm{ZnSO}_{4}$ und $\mathrm{Ba}(\mathrm{OH})_{2}$ behandelt werden, da sonst eine rückläufige Schleichreaktion auftritt.

\section{Präzision der Metbode}

Die Glucosekonzentration wurde in verschiedenen Standardlösungen und Kontrollproben an mehreren Tagen dreifach mit dem Endpunktautomaten 5030 be-

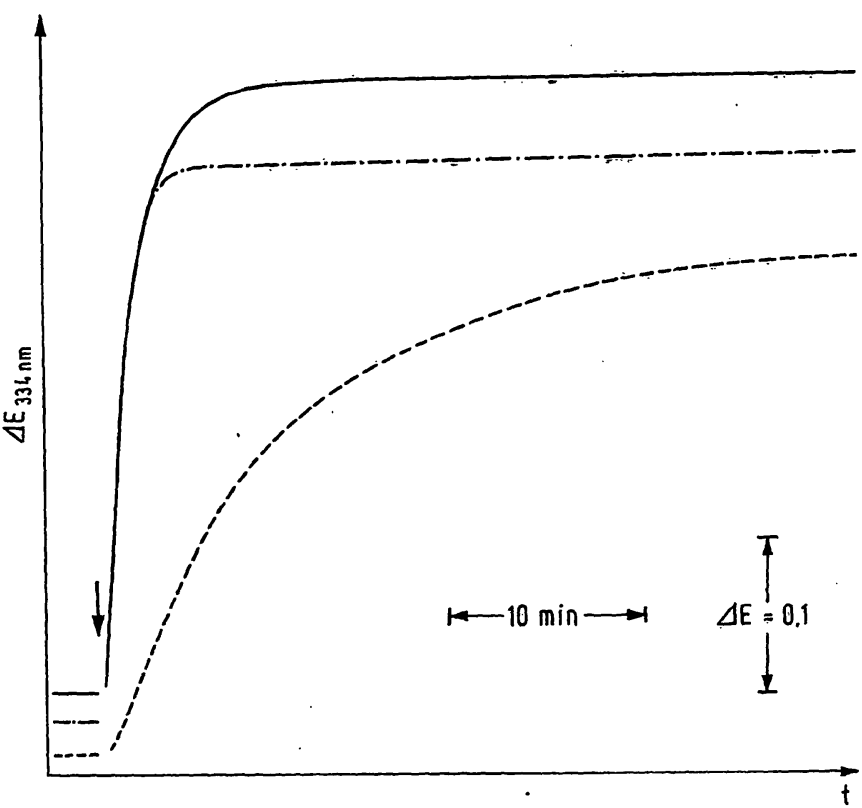

Abb. 3

Der Ablauf der Glucosereaktion bei $334 \mathrm{~nm} .20 \mu l$ einer wäßr. Glucoselösung $(10 \mathrm{mmol} / \mathrm{l})$ wurden wie unter Methodik angegeben mit $\mathrm{ZnSO}_{4} /$ $\mathrm{Ba}(\mathrm{OH})$, behandelt. Nach dem Abschleudern wurden $100 \mu 1$ des Öberstandes (Pfeil) zu $500 \mu$ l Reaktionslösung (mit - - - - und ohne -Glutathion) gegeben. Bei der Kontrolle $(\longrightarrow$ wurden $20 \mu \mathrm{l}$ der Glucoselösung mit $600 \mu 1$ bidest. $\mathrm{H}_{2} \mathrm{O}$ verdünnt (Die Reaktionslösung enthielt kein Glutathion) Küvettentemperatur: $20^{\circ} \mathrm{C}$

Tab. 3

Die Effektivität verschiedener kationischer und anionischer Enteiweißungsmittel bei der Probenvorbereitung für die mechanisierte Bestimmung der Glucosekonzentration mit der Hexokinasemethode. 20 Mikroliter Monitrol I bzw. heparinisiertes Humanblut wurden in $500 \mu$ I Enteiweißungsmittel dosiert. Rotationsmischer: $2 \mathrm{~min}$. Zentrifugation: $2 \mathrm{~min}, 12000 \mathrm{U} / \mathrm{min}$. Der Überstand (obere Hälfte) wurde bei $334 \mathrm{~nm}$ gegen bidest. $\mathrm{H}_{2} \mathrm{O}$ gemessen bzw. für kinetische Untersuchungen (500 $\mu 1$ Reaktionslösung $+50 \mu 1$ Überstand) verwendet

\begin{tabular}{|c|c|c|c|c|}
\hline Enteiweißungsmittel & $\begin{array}{c}\Delta E \\
\text { Monitrol I }\end{array}$ & $\begin{array}{l}10 \\
\text { Blut }\end{array}$ & $\begin{array}{c}\text { Hemmung der Hexokinase-I } \\
\text { Glucose-6-phosphat-dehydro- } \\
\text { genase-Reaktion }\end{array}$ & Bemerkung \\
\hline $\begin{array}{l}\left(\mathrm{NH}_{4}\right)_{2} \mathrm{SO}_{4} \text {, gesätt. } \\
\text { Trichloressigsäure } 10 \mathrm{~g} / 100 \mathrm{ml} \\
\text { Perchlorsäure } 0,33 \mathrm{~mol} / 1 \\
\text { Metaphosphorsäure } 1 \mathrm{~g} / 100 \mathrm{ml} \\
\mathrm{ZnSO}_{4}+\mathrm{Ba}\left(\mathrm{OH}_{2}\right)_{2} \\
\mathrm{ZnSO}_{4}+\text { Äthanol }\end{array}$ & $\begin{array}{l}\text { nein } \\
\text { ja } \\
\text { nein } \\
\text { ja } \\
\text { ja } \\
\text { ja }\end{array}$ & $\begin{array}{c}\text { nein } \\
\text { ja } \\
\text { nein } \\
\text { ja } \\
\text { ja } \\
\text { ja }\end{array}$ & $\begin{array}{c}t \\
+t+ \\
+ \\
+13 \\
\left.+++^{2}\right) \\
\left.+++^{2}\right)\end{array}$ & $\begin{array}{c}\text { unstabil } \\
2 \text { Dosierungen } \\
\text { verdunstet } z u \text { rasch }\end{array}$ \\
\hline
\end{tabular}

3) Teilweise umkehrbar durch Erhöhung der $\mathrm{Mg}^{2+-}$-Konzentration.

2) Umkehrbar durch Glutathion. 


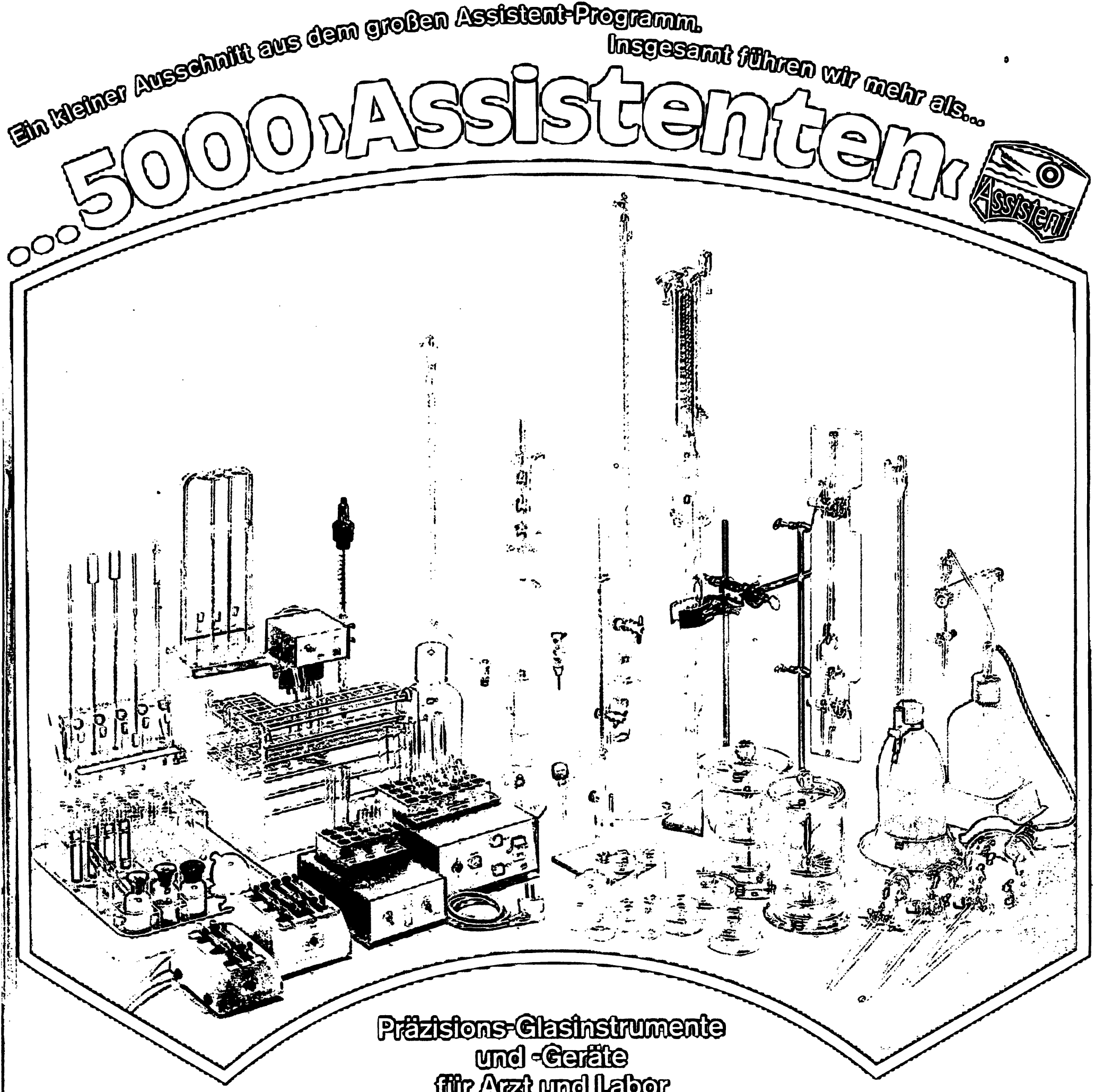

Wit fowhren folgende Artikel-Gruppens

Bluturntersuchurngs:lnstrumente

Bluts Enzymat Kapillarsipetten alles Arts auch mit Doleranz: angabe auf dem Gerât und amflich geeichts Zählkammern in Prấzisionsausführung sowie amtlich geeichts Blutsenkungss apparate, Haemometer, Pipeften=Schuttèlgeräte usw. Labortabletts

futr Blutbild und Blutzucker, Medikamentenfablett

Orinprober Ureometer, Albuminimeter, Zentrifugens und Ưtnmeßĝtâser

Maßanalytische Geraftes Mikropipetten für Elmmalgebrauch, MeßBzylinder, Mensuren, MeBflaschen, Büretten - auch mit automatischer Null punk kt: Einstellung 2.B. nach Schilling; Tituters apparate - auch als Spezialmodell fü̈p Reagenzlenoflaschen

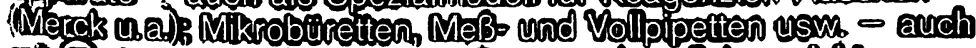
mit Toleranzangabe auf dem Gerât und amullich geetcht Parbegerfite

Schalem, Gestelle Tröge, Elinsatze (auch für die Papanicolaou:

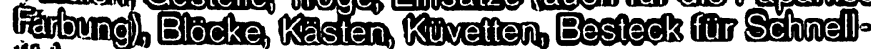
tatbung cba.
Reagenzzläser in verschiedenen Glasqualitätev sowie vielen GrôBen und Ausfienthungen

Aufbewahrungsgestelle

aus Mollz und Plexiglas für Reagenzg/äser, Zentrifugengläser und Küureften; fernees für Pipetten un verschtedenen Größen

Mukroskoplsche Deckgläser und Objekttrâger

instrumentenschalen, Wattezyllinder, Standzylinder, Glas:

dosen usw

- Versandgefäae für infektiōses Matertal uswo

Thermostate, Veraschungsgestelle

Schlliffgerfite Hähne, Kühler, Scheidetrichter uswo

Panas-Wagner-Gerfate für die KjeldahikRest:N:Bestimmung Wasserbadgestelle aus Edelstahl oder Messing vernickelts ound oder rechteckig

Sämitliche Assistent:Erzeugnitsse erhalten Sie in Fachgeschätt 


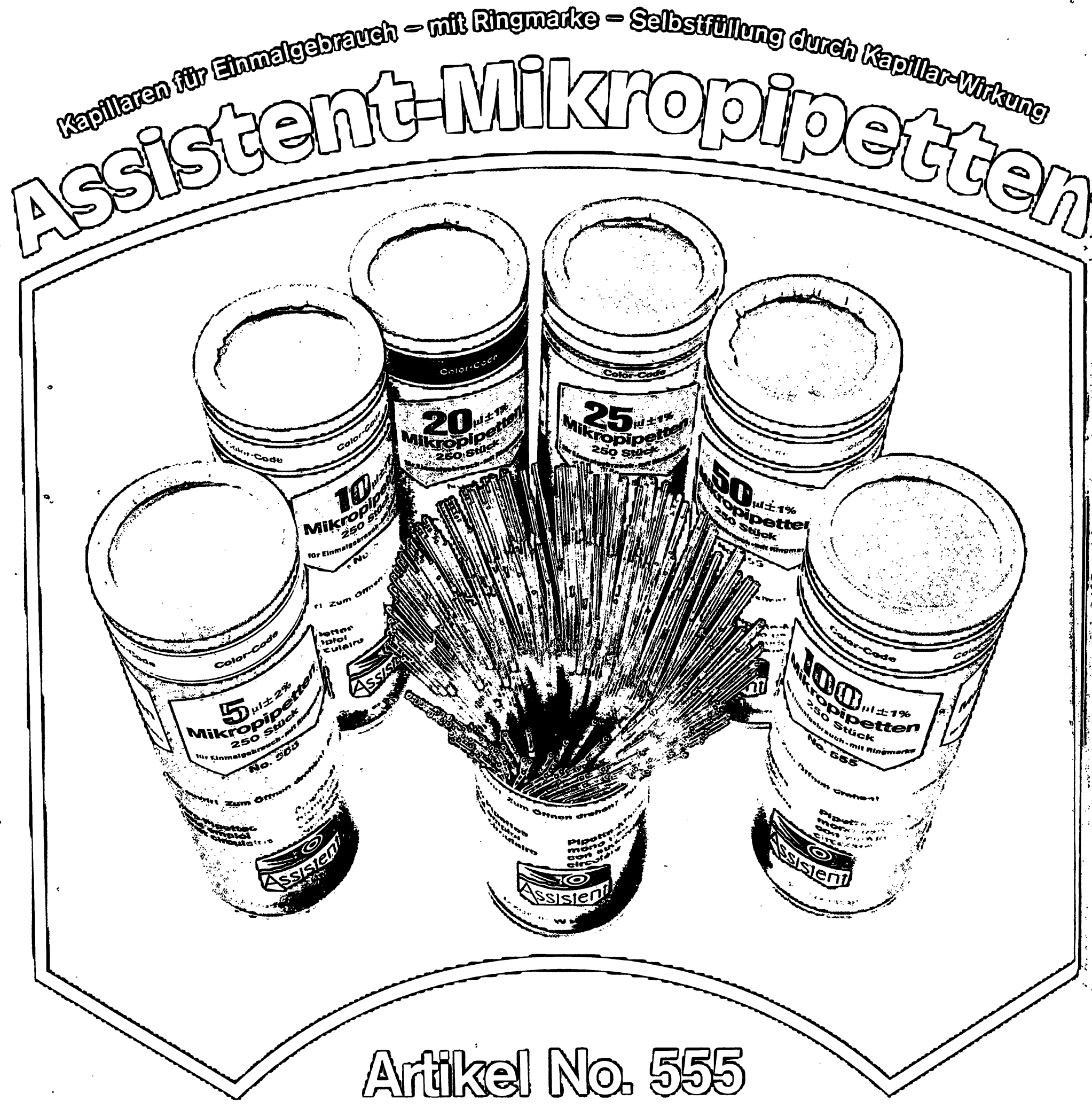

Assistent:Mikropipetten ersparen das lästige zeitraubende Reinigens Denn sie sind füp Einmalgebrauch besthumb Rafionelle Arbeitsweise - vorteilhafter Preis!

Assistent:Mikropipetten sind vơn hôchster Prâzistion. Sie ent sprechen nach 5 6.1.1. der Eichpflichts Ausnahmeverordnung sinngemäß den einschlägigen Vorschuiften der Euchordnung,

Assistent:Mikroptpetten gibtes to 6 verschledenen Grổenen $5 \mathrm{cmm}, 10 \mathrm{cmm}, 20 \mathrm{cmm}, 25 \mathrm{cmm}, 50 \mathrm{cmm}$ und $100 \mathrm{cmm}$. lede Packung enthält 250 Mikropipetten sowle ethen LatexSchlauch mit Mundsfück und Adapter.

Sämtliche Assistent:Erzeugnisse erhalten Sie tro Fach geschaft (Thr Fach handles hat auch unseren großen Katalog zur Verfügungs er enthâlit mêtr als 5.000 verschiledene Prâzistons? Glasinstrumente und -Gerâte füts Arzit und Laboril

Glaswarenfabrik

Katrit Hechit

Pratisions-Glastnstrumente

und - Gerâte fols Arzit und Labor

D8745 SondheitulRhôn Tel. $(09754) 259$ Telex 0672865

Dro24Bernhausen/Stuttgant Teb. (071i) 793533 Telex 255625
CHA8595 Altnau TG/Schwetz Tel. $(072) 67222$

F92LePlessis:Roblinson/Paris 84 Rue Bernard Iské tèb $655 \% 01:$ A6122 Fritzens/Tirol Bergstraße6. Tel. (05224) 2646 : 
Tab. 4

Präzision der Glucosebestimmung mit dem Endpunktautomaten. Die Proben wurden entweder in jeder Serie wie unter Methodik beschrieben enteiweißt (A) oder in einem großen Ansatz (B) mit $\mathrm{ZnSO} / \mathrm{Ba}(\mathrm{OH})$, versetzt und zentrifugiert. Ein Aliquot des Überstandes $B$ wurde täglich in den Automaten eingesetzt und wie jede Probe dreifach bestimmt: aus dem 2. und 3. Wert wurde die Präzision in der Serie, aus dem 2. Wert die Präzision von-Tag-zu-Tag berechnet. C: Glucosebestimmung mit Probenleerwert. Die Probenvorbereitung erfolgte nach Verdünnungsstufe I oder II

\begin{tabular}{|c|c|c|c|c|c|c|c|c|c|}
\hline \multicolumn{2}{|r|}{ Probe } & \multicolumn{4}{|c|}{ Präzision in der Serie } & \multicolumn{4}{|c|}{ Präzision von Tag zu Tag } \\
\hline & & $\frac{\overline{\mathbf{x}}}{[\mathrm{mmol} / 1]}$ & $\stackrel{\mathrm{s}}{[\mathrm{mmol} / \mathrm{l}]}$ & $\mathrm{n}$ & $\begin{array}{l}V_{\mathbf{s}} \\
{[\%]}\end{array}$ & $\begin{array}{c}\overline{\mathbf{x}} \\
{[\mathrm{mmol} / 1]}\end{array}$ & $\stackrel{\mathrm{s}}{[\mathrm{mmol} / \mathrm{l}]}$ & $\mathrm{n}$ & $\begin{array}{l}V K_{d} \\
{[\%]}\end{array}$ \\
\hline $\mathbf{A}$ & $\begin{array}{l}\text { Kontrollserum } \\
\text { (Behring) }\end{array}$ & 5,73 & 0,07 & 53 & 1,3 & 5,73 & 0,11 & 55 & 2,0 \\
\hline \multirow[t]{5}{*}{ B } & wäßr. Standard & 1,03 & 0,04 & 20 & 3,4 & 1,04 & 0,08 & 19 & 6,8 \\
\hline & & 2,03 & 0,03 & 20 & 1,4 & 2,03 & 0,07 & 21 & 3,3 \\
\hline & & 5,04 & 0,05 & 22 & 0,6 & 5,05 & 0,08 & 22 & 1,7 \\
\hline & & 10,00 & 0,05 & 18 & 0,5 & 10,01 & 0,12 & 18 & 1,2 \\
\hline & & 24,16 & 0,11 & 21 & 0,5 & 24,64 & 0,31 & 17 & 1,2 \\
\hline \multirow[t]{3}{*}{ c } & Kontrollurin (1) & 4,81 & 0,11 & 24 & 2,3 & 4,81 & 0,16 & 24 & 3,3 \\
\hline & wäßr. Standard (I) & 25,16 & 0,19 & 20 & 0,8 & 24,97 & 0,32 & 20 & 1,3 \\
\hline & wäßr. Standard (II) & 204,48 & 1,16 & 20 & 0,6 & 204,60 & 3,97 & 20 & 1,9 \\
\hline
\end{tabular}

stimmt. Der erste Wert wurde wegen eventueller Verschleppungseffekte verworfen. Der zweite und dritte Wert diente zur Ermittlung der Präzision in der Serie und der von-Tag-zu-Tag (Tab. 4).

Unter den gleichen Bedingungen wurde die Streuung in der Serie von Leerwerten (Wasser als Probe) an 20 Tagen ermittelt. Die dreifache Standardabweichung ist nach KAISER (18) ein Maß für die Nachweisgrenze: 0,1 mmol/l. Wenn die Probendosierung auf der Station, also nicht durch technische Assistentinnen erfolgt, ist eine regelmäßige Unterweisung des Proben abnehmenden Personals erforderlich. Wir haben 30 Mitarbeiter unseres Routinelabors nach einmaliger Einweisung in die Handhabung der Glaskapillaren aus 2 Kontrollproben je 1 Probe entnehmen lassen, die Glucosekonzentration mit dem Endpunktautomaten in einer Serie bestimmt und die Streuung der Einzelwerte berechnet. Dabei wurde ein Variationskoeffizient von $2,6 \%$ mit Asid-Kontrollserum $(4,6 \mathrm{mmol} / \mathrm{l})$ und von $1,7 \%$ mit Monitrol II (13,6 mmol/l) erreicht. Dieser Versuch zeigt, daß die Streuung um etwa das zweifache ansteigt, wenn die Dosierung durch verschiedene Personen erfolgt. Trotz-

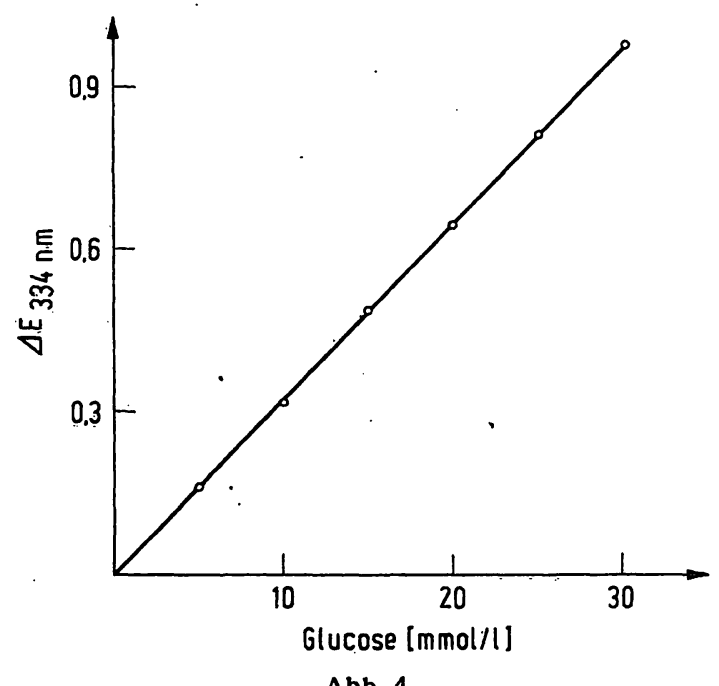

Abb. 4

Eichgerade bei der Glucosebestimmung. Glucoselösungen mit verschiedenen Konzentrationen wurden wie Proben behandelt, nach $\mathrm{Ba}(\mathrm{OH})_{2}-\mathrm{Zugabe}$ abgeschleudert und anschließend im Endpunktautomaten analysiert. Es handelt sich um Mittelwerte aus 5 Bestimmungen dem ist die Präzision unter diesen Bedingungen noch zufriedenstellend.

\section{Richtigkeit}

Die Eichkurve verläuft bis zu einer Konzentration von $30 \mathrm{mmol} / \mathrm{l}$ weitgehend linear (Abb. 4). Jedoch sollten Proben ab $25 \mathrm{mmol} / \mathrm{l}$ verdünnt werden ( $50 \mu \mathrm{l}$ Überstand $+500 \mu 1 \mathrm{ZnSO}_{4}$-Lösung), da bei höheren Konzentrationen gelegentlich eine geringe Schleichreaktion beobachtet wird.

Eine Serie von etwa 120 Patientenproben wurde mit Perchlorsäure und $\mathrm{ZnSO}_{4} / \mathrm{Ba}(\mathrm{OH})_{2}$ deproteinisiert und anschließend im Endpunktautomat 5030 auf Glucose analysiert. Bei Perchlorsäure-Enteiweißung wurde ein Probenleerwert vom Ergebnis abgezogen (BilirubinProgrammstecker). Das Ergebnis der Regressionsanalyse ist in Abb. 5 dargestellt.

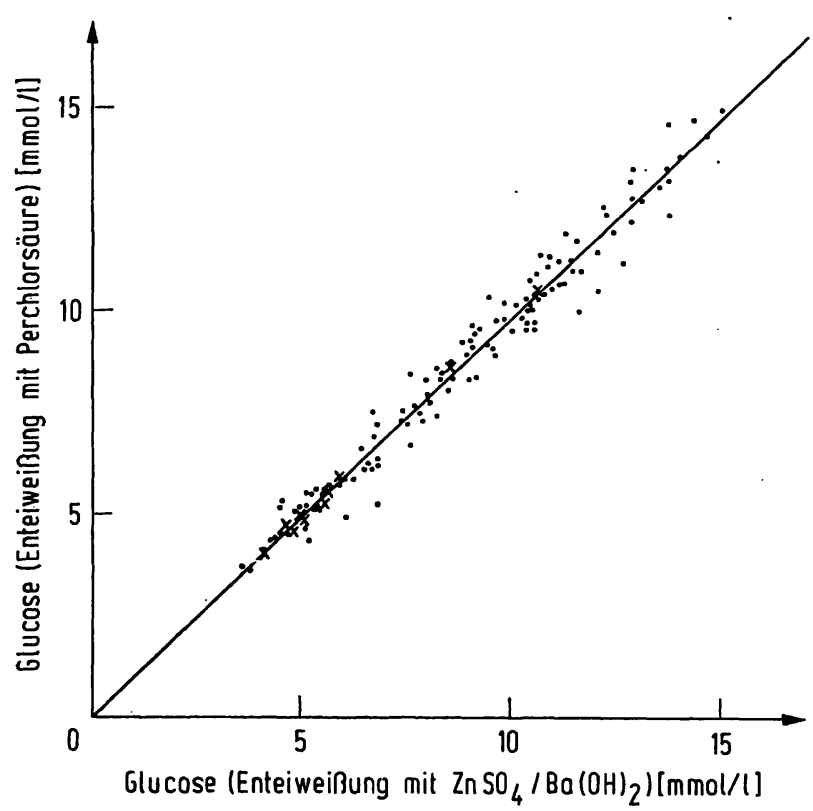

Abb. 5

Korrelation der mit der Hexokinase-Methode gefundenen Glucosekonzentrationen bei unterschiedlicher Enteiweißung. Bei der Enteiweißung mit Perchlorsäure wurde ein Probenleerwert vom Ergebnis abgezogen und Glutathion in der Reaktionslösung durch Triäthanolamin-Puffer ersetzt. Einige trübe und lipämische Seren (Kreuze) wurden ebenfalls untersucht
$y=0,9863 x+0,0805 ; r=0,9840$ 
Die Richtigkeit des modifizierten Verfahrens wurde außerdem durch Wiederfindungsversuche geprüft, deren Ergebnisse in Tabelle 5 zusammengestellt sind.

Vor kurzem hatten wir berichtet, daß eingewogene Glucosemengen um etwa $4 \% \mathrm{zu}$ hoch wiedergefunden werden, wenn das Ergebnis mit Hilfe des Extinktionskoeffizienten von NADH, bzw. NADPH bei $366 \mathrm{~nm}$ berechnet wird (19). Dieser Befund wurde inzwischen auch von anderer Seite bestätigt (20). Wird bei $334 \mathrm{~nm}$ gemessen, wird die eingewogene Glucosemenge annähernd wiedergefunden (19). An 60 Tagen ermittelten wir mit einer wäßrigen Glucoselösung von $10 \mathrm{mmol} / \mathrm{l}$ den Berechnungsfaktor, mit dem die erhaltenen Extinktionsdifferenzen unter unseren Bedingungen $\mathrm{zu}$ multiplizieren sind: $30,85 \pm 0,42$. Dieser Wert stimmt mit dem theoretischen Wert von $31,00\left(\varepsilon_{334 \mathrm{~nm}}=6: 10^{6}\right.$ $\mathrm{cm}^{2} / \mathrm{mol}(21)$ ) gut überein.

Die Genauigkeit der Glaskapillaren wurde durch 10 Auswägungen mit bidest. Wasser an einer Halbmikrowaage (Sartorius) geprüft: $19,94 \pm 0,45 \mu$ l. Der Variationskoeffizient betrug $0,2 \%$, die Abweichung vom Sollwert $-0,3 \%$ (Die Raumtemperatur wurde bei den Berechnungen berücksichtigt).

Die Eiweißpräzipitation führt zu einem Volumenverdrängungsfehler. Der durch das Erythrocytenvolumen bewirkte Fehler beträgt unter unseren experimentellen Bedingungen bei Kapillarblut etwa 0,5\% und kann entsprechend berücksichtigt werden (22). Diese Korrektur erscheint jedoch fraglich, da 2 Größen (spezifisches Gewicht und Flüssigkeitsgehalt des Blutes) verwendet werden, deren Konstanz bei Patientenblut nicht gewährleistet ist. Aus den gleichen Gründen beachten wir den durch die Fällung der Proteine verursachten Volumenfehler nicht, der im Mittel 0,16\% beträgt, wenn man für das spezifische Volumen der Serumproteine einen durchschnittlichen Wert von 0,725 einsetzt (23).

\section{Verscbleppungseffekte}

Der prozentuale Verschleppungskoeffizient (Q) nach Hjelm (24) wurde wie kürzlich beschrieben (25) an 20 Tagen aus einer täglichen Serie von Glucoselösungen (je $5 \mathrm{mal} 2 \mathrm{mmol} / \mathrm{l}, 20 \mathrm{mmol} / \mathrm{l}, 2 \mathrm{mmol} / \mathrm{l}$ ) bestimmt (Abb.6). Der prozentuale Koeffizient für die Verschleppung von niedrigen zu hohen Konzentrationen $\left(Q_{1}\right)$ und für die Verschleppung von hohen zu niedrigen Konzentrationen $\left(\mathrm{Q}_{2}\right)$ sind etwa gleich groß und liegen im Durchschnitt bei $0,9 \%$ (Abb. 6).

Aus den Q-Werten kann nicht ohne weiteres ersehen werden, ob bei einer Methode Verschleppungsfehler vernachlässigt werden dürfen. Daher haben wir kürzlich (25) ein Verfahren vorgeschlagen, mit dessen Hilfe die graphische Darstellung eines sogenannten verschleppungssicheren Bereiches möglich ist. Dabei wird die Verschleppung mit der methodischen Streuung in Beziehung gesetzt. Ermittelt man so den verschleppungssicheren Bereich, zeigt sich, daß dieser nicht den ganzen Meßbereich umfaßt (Abb. 6). Bei Werten über $10 \mathrm{mmol} / \mathrm{l}$ sollte überlegt werden, ob die nachfolgende Analyse,

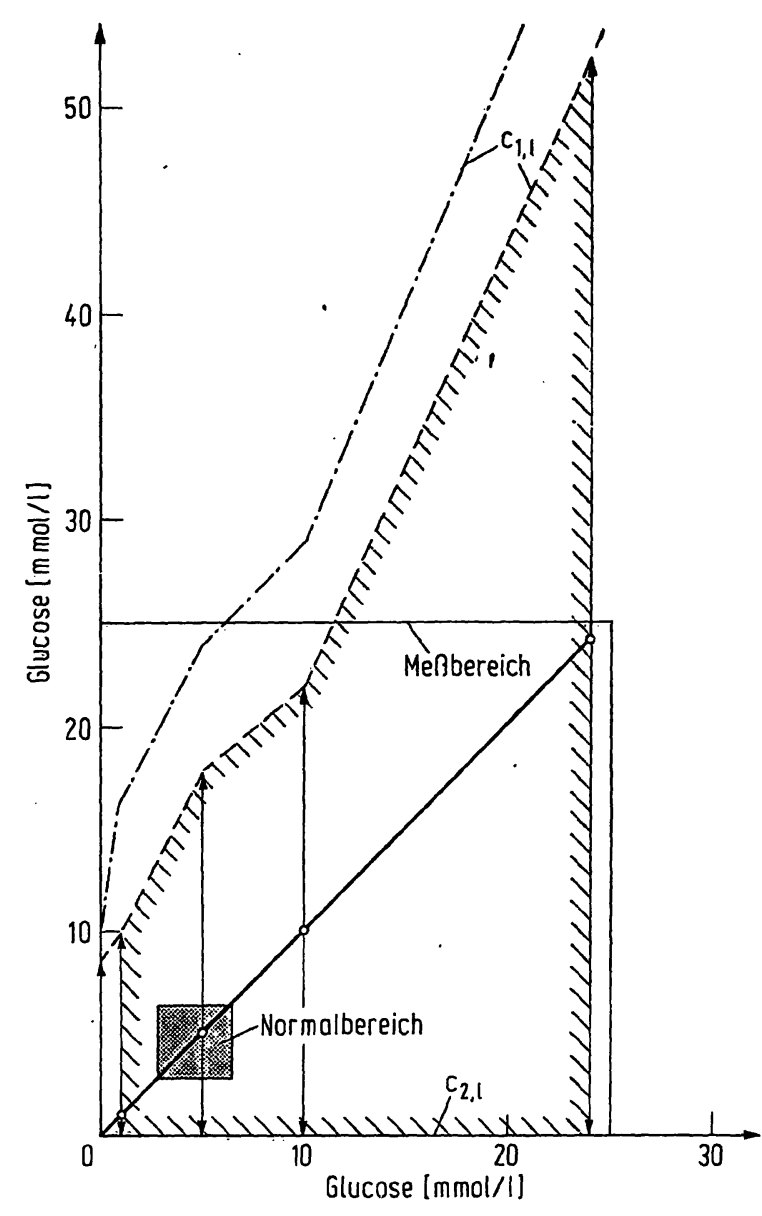

Abb. 6 Der verschleppungssichere Bereich (gestrichelte Linie) bei der Glucose-
bestimmung mit dem Endpunktautomaten 5030 Die Grenzkonzentrationen für die Verschleppung von niedrigen zu hohen $\left(c_{1}, 1\right)$ una von hohen zu niedrigen Konzentrationen $\left(c_{2}, 1\right)$ zu den durch Punkte markierten Konzentrationen wurden nach l. c. (25) berechnet. Die entsprechenden Standardabweichungen wurden der Tabelle 4 entnommen. Den Berechnungen liegt das Postulat zugrunde daß der Verschleppungsfehler kleiner als der zweifache Bereich $(--\rightarrow)$, bzw. kleiner als der dreifache Bereich $(-\cdot-)$ der methodischen Streuung in der Serie (Standardabweichung) sein soll. Prozentuale Verschleppungskoeffizienten $Q_{1}=0,9 \pm 0,6 \%, Q_{2}=0,8 \pm 0,2 \%$ (Mittelwerte von 20 Bestimmungen an verschiedenen Tagen mit Standardabweichung)

falls deren Konzentration unter $10 \mathrm{mmol} / 1$ liegt, wiederholt werden muß. So darf $z$. B. eine Probe mit $5 \mathrm{mmol} / \mathrm{l}$ Glucose auf eine andere mit einer Konzentration von bis zu $18 \mathrm{mmol} / \mathrm{l}$ folgen, ohne daß der Verschleppungsfehler berücksichtigt werden muß. Hat die vorangehende Probe einen höheren Glucosegehalt, muß die nachfolgende Messung entweder wiederholt oder korrigiert werden. Verschleppungsfehler von niedrigen zu hohen Konzentrationen können innerhalb des ganzen Meßbereiches vernachlässigt werden (Abb. 6). Liegt ein Wert außerhalb des Meßbereiches, muß die nachfolgende Probe grundsätzlich nochmals analysiert werden. Dieses Prinzip gilt aber für alle Methoden, die mit Verschleppungsfehler behaftet sind.

\section{Drift}

Um den Aufwand einer Driftkorrektur zu vermeiden, wählen wir die Segmentlänge in einer Serie so, daß die Extinktionswerte einer Standardlösung, die etwa im mittleren Meßbereich liegt, nicht mehr als $1 \%$ zu- oder abnehmen. An 20 Tagen driftete das Ergebnis einer 
$10 \mathrm{mmol} / \mathrm{l}$ Glucoselösung nach 20 Proben im Anfangssegment im Durchschnitt um 0,6\%. Auch nach einigen Zwischensegmenten nahm im Endsegment diese Drift nicht zu. Daher ist eine einmalige Driftkontrolle im Anfangssegment einer Serie ausreichend.

\section{Interferenzen}

BarthelmaI (26) untersuchte den Einfluß von Bilirubin, Lipiden, Sulfonamiden und einer Reihe anderer Medikamente auf die Hexokinase- und Glucose-6-phosphat-dehydrogenase-Reaktion. Dabei wurde keine Interferenz festgestellt. Fructose führt wegen der Verunreinigung der Hexokinase und Glucose-6-phosphatdehydrogenase (4) an Phosphohexoseisomerase zu einem positiven Fehler, der allerdings nur bei hohen Fructosekonzentrationen beachtet werden muß: $20 \mathrm{mmol} / \mathrm{l}$ Fructose bewirken eine scheinbare Glucosekonzentration von $0,53 \mathrm{mmol} / \mathrm{l}$. Selbst bei Infusion dieses Zuckers ist somit eine grobe Fehlbestimmung der Glucose nicht zu erwarten. Reduziertes Glutathion aktiviert unter den vorgeschlagenen Testbedingungen den Fructoseumsatz nicht.

Eine erhebliche Interferenz kann bei extrem lipämischen Blutproben auftreten, da der Uberstand nach der Enteiweißung bei $334 \mathrm{~nm}$ noch Licht absorbiert (Tab. 6).
Allerdings wird der zu erwartende Fehler bei einer Glucosekonzentration von $5 \mathrm{mmol} / \mathrm{l}$ erst mit Triglyceridkonzentrationen, die über $18 \mathrm{mmol} / 1$ liegen, größer als 3\%. Extrem hohe Triglyceridwerte können jedoch zu einer fatalen Verfälschung der Ergebnisse führen. In solchen Fällen kann man $1,5 \mathrm{ml}$ Serum in Reaktionsgefäßen etwa $1 \mathrm{~h}$ zentrifugieren (Eppendorf Zentrifuge 5411, Nenndrehzahl $16000 \mathrm{U} / \mathrm{min}$, etwa $12000 \mathrm{~g}$ ). Danach wird die oberste Fettschicht vorsichtig mit einer Pipettenspitze oder einem Spatel abgehoben und aus dem unteren Drittel mit einer Eppendorf Pipette 200-300 $\mu \mathrm{l}$ Serum entnommen. Dieses Aliquot eignet sich sowohl für die Bestimmung von Enzymaktivitäten als auch von verschiedenen Metaboliten. Bei diesem Vorgehen lag die Extinktion des Überstandes nach der $\mathrm{ZnSO}_{4} / \mathrm{Ba}(\mathrm{OH})_{2}$-Enteiweißung bei einer Serumprobe, die $37,38 \mathrm{mmol} / 1$ Triglyceride enthielt, unter 0,010 $(\overline{\mathrm{x}}=0,005, \mathrm{~s}=0,002, \mathrm{n}=5)$.

\section{Liquor}

Das oben beschriebene Verfahren eignet sich auch für die Bestimmung der Glucosekonzentration in Liquor. 15 Proben von verschiedenen Patienten wurden sowohl mit Perchlorsäure als auch mit $\mathrm{ZnSO}_{4} / \mathrm{Ba}(\mathrm{OH})_{2}$ enteiweißt und der Überstand im Endpunktautomat 5030

Tab. 5

Wiederfindung von Glucose in Blut-, Urin- und Serumproben. Es handelt sich um Mittelwerte (mmol/l) aus 5 Bestimmungen. Experimentelle Bedingungen: Siehe unter Methodik

\begin{tabular}{|c|c|c|c|c|}
\hline Probe & $\begin{array}{c}\text { Glucosekonzentration } \\
\text { ohne Zusatz }\end{array}$ & $\begin{array}{c}\text { Addierte } \\
\text { Glucosekonzentration }\end{array}$ & $\begin{array}{l}\text { Wiedergefundene } \\
\text { Glucosekonzentration }\end{array}$ & Differenz \\
\hline Blut & 4,06 & 3,33 & 3,31 & $-0,6 \%$ \\
\hline Blut & 3,26 & 3,33 & 3,35 & $+0,6 \%$ \\
\hline Serum & 6,42 & 3,33 & 3,33 & 0 \\
\hline Urin & 0,22 & 3,33 & 3,36 & $+0,9 \%$ \\
\hline Urin & 0,64 & 3,33 & 3,34 & $+0,3 \%$ \\
\hline Urin & 6,22 & 8,33 & 8,30 & $-0,4 \%$ \\
\hline
\end{tabular}

Tab. 6

Der Einfluß von Lipiden auf die Extinktion des Öberstandes nach der $\mathrm{ZnSO} / \mathrm{Ba}(\mathrm{OH})_{2}$-Behandlung von Kapillarblut und Serum eines $\mathrm{Patienten}$ mit einer Hyperlipämie. Die Proben wurden an verschiedenen Tagen entnommen

\begin{tabular}{|c|c|c|c|c|}
\hline Probe & $\begin{array}{c}\Delta \mathrm{E}_{334} \\
\overline{\mathrm{x}}(\mathrm{s}), \mathrm{n}=5\end{array}$ & $\begin{array}{c}\text { Zu erwartender Fehler } \\
\text { bei einer Glucose- } \\
\text { konzentration von } \\
5 \mathrm{mmol} / 1\end{array}$ & $\begin{array}{c}\text { Triglyceridkonzen- } \\
\text { tration im Serum, } \\
\left.\text { mmol/ } 1^{1}\right)\end{array}$ & $\begin{array}{c}\text { Cholesterinkonzen- } \\
\text { tration im Serum, } \\
\text { mmol/1²) }\end{array}$ \\
\hline Kapillarblut & $\begin{array}{c}0,002 \\
(0,001)\end{array}$ & $0,2 \%$ & 6,79 & 8,4 \\
\hline Serum & $\begin{array}{c}0,375 \\
(0,214)\end{array}$ & $39 \%$ & 37,38 & 14,3 \\
\hline Verdünntes Serum") & $\begin{array}{c}0,024 \\
(0,003)\end{array}$ & $2,5 \%$ & $\left.18,69^{3}\right)$ & $\left.7,2^{3}\right)$ \\
\hline Verdünntes Serum²) & $\begin{array}{c}0,009 \\
(0,004)\end{array}$ & $0,9 \%$ & $\left.12,46^{2}\right)$ & $\left.4,8^{3}\right)$ \\
\hline Verdünntes Serum²) & $\begin{array}{c}0,005 \\
(0,002)\end{array}$ & $0,5 \%$ & $\left.9,35^{3}\right)$ & $\left.3,6^{3}\right)$ \\
\hline Verdünntes Serum²) & $\begin{array}{c}0,005 \\
(0,001)\end{array}$ & $0,5 \%$ & $\left.6,23^{3}\right)$ & $\left.2,4^{3}\right)$ \\
\hline Albuminlösung $7 \mathrm{~g} / 100 \mathrm{ml}$ & $\begin{array}{c}0,004 \\
(0,001)\end{array}$ & $0,4 \%$ & 0,16 & \\
\hline
\end{tabular}

2) Mittelwert aus Doppelbestimmungen.

2) $100 \mu$ l Serum $+100,200,300$ oder $500 \mu \mathrm{l}$ Albuminlösung (7 g/100 ml bidest. $\left.\mathrm{H}_{\mathbf{3}} \mathrm{O}\right)$.

) berechnet. 
auf seinen Glucosegehalt untersucht; der berechnete Korrelationskoeffizient betrug

$$
r=0,9653(y=1,0106 \cdot x-0,1481
$$

$y$-Werte: Enteiweißung mit Perchlorsäure).

\section{Urin}

Die von uns getesteten Enteiweißungsmittel entfernen nicht alle bei $334 \mathrm{~nm}$ absorbierenden Substanzen aus dem Überstand. Deshalb ist es beim Endpunktautomaten unerläßlich, einen Probenleerwert ( $50 \mu \mathrm{l}$ Überstand $+500 \mu \mathrm{l}$ Leerwertlösung) mitzubestimmen (Bilirubin-Programmstecker). Dieser lag bei 79 Patienten zwischen $\Delta \mathrm{E}=0,005$ und $\Delta \mathrm{E}=0,104(\overline{\mathrm{x}}=0,034)$. Präzision (Tab. 4) und Nachweisgrenze $(0,15 \mathrm{mmol} / \mathrm{l})$ werden durch das Mitführen des Probenleerwertes etwas beeinflußt. Wir begrenzen die Segmentlänge hier ebenfalls auf 20 Proben und überprüfen danach den Nullabgleich der beiden Durchflußküvetten. Die Leerwertlösung kann nicht durch Wasser oder Puffer ersetzt werden. Aufgestockte Glucosemengen wurden mit Abweichungen von weniger als $1 \%$ wiedergefunden (Tab. 5).

50 Patientenurine wurden mit Perchlorsäure und mit $\mathrm{ZnSO}_{4}$ enteiweißt und im Endpunktautomaten auf den Glucosegehalt untersucht. Dabei fand sich eine ausreichende Korrelation $\quad(y=0,9777 x+0,0647$, $r=0,9976, y$-Werte: Enteiweißung 'mit Perchlorsäure).

$\mathrm{Da}$ die Glukosekonzentration im Urin wesentlich stärker schwankt als im Blut, ist die Beachtung des Verschleppungsfehlers hier besonders wichtig. Die Probenkette wird daher so zusammengestellt, daß nach den Kontrollproben zuerst ein Wasserwert, dann die Diastix-negativen und zuletzt die -positiven Proben eingesetzt werden.

\section{Diskussion}

Die Bestimmung der Glucosekonzentration mit der Hexokinase-Methode wird in biologischen Materialien meist nach Abtrennung der Proteine durchgeführt. Bei Verwendung der Glucose-6-phosphat-dehydrogenase für die Indikatorreaktion wird heute mit Perchlorsäure (2), bei Pyruvatkinase und Lactatdehydrogenase als Hilfs- bzw. Indikatorenzym mit Trichloressigsäure (27) enteiweißt. In Blutproben kann die Hexokinase-Methode auch nach vorheriger Hämolyse ohne Ausfällung der Proteine $(12,28,29)$ durchgeführt werden. Dieses Verfahren läßt sich jedoch vorerst nur mit Flow-Systemen mechanisieren.

Ein für die Mechanisierung der Hexokinase-Methode ideales Enteiweißungsmittel sollte

1. keine Eigenabsorption haben,

2. alle zwischen 334 und $366 \mathrm{~nm}$ absorbierenden Substanzen ausfällen,

3. nur einen Pipettierschritt erfordern,

4. die im Überstand durchzưühhrenden Reaktionen nicht hemmen und

5. einige Wochen haltbar sein.
Die Beständigkeit eines frisch angesetzten Fällungsmittels spielt dann eine Rolle, wenn die Proben nach dem von HILGER et al. (11) beschriebenen Verfahren vom Pflegepersonal auf den Stationen dosiert werden sollen. Keines der von uns für die Glucosebestimmung nach der Hexokinase-Methode untersuchten Enteiweißungsmittel (Tab. 3) erfüllt die genannten Bedingungen vollständig, so daß bei der Wahl eines der üblichen Verfahren immer ein Kompromiß 'eingegangen werden muß.

Trichloressigsäure bewirkt $z$ war bei der Enteiweißung von Blutproben eine geringere Extinktionsdifferenz bei $334 \mathrm{~nm}$ als Perchlorsäure, kann aber nicht verwendet werden, da sie die Glucose-6-phosphat-dehydrogenase stark hemmt. Pfleidererer und Grein (27) beschirieben ein Verfahren zur Glucosebestimmung, bei dem im Trichloressigsäure-Überstand das bei der Hexokinasereaktion entstehende ADP mit Hilfe der Pyruvatkinase und Lactatdehydrogenase nachgewiesen wird. Bei dieser Methode wird jedoch die Unspezifität der Hexokinase nicht durch die nachfolgende Indikatorreaktion ausgeglichen.

Mit Metaphosphorsäure (30) und alkoholischer Zinksulfatlösung wird zwar der Überstand von B̈lutproben ausreichend geklärt, jedoch ist bei diesem Enteiweißungsmittel die Vorlage für den Routinebetrieb eines großen Klinikums bei Raumtemperatur nicht beständig genug. Unter solchen Bedingungen erscheint die Ausfällung der Proteine mit $\mathrm{ZnSO}_{4}$ und $\mathrm{Ba}(\mathrm{OH})_{2}$ am zuverlässigsten. Allerdings sind dabei 2 Pipettierschritte erforderlich.

$\mathrm{Ba}(\mathrm{OH})_{2}$ kann nur bei Kapillarblut (15) und klaren Seren durch $\mathrm{NaOH}(0,1 \mathrm{~mol} / \mathrm{l})$ ersetzt werden. Bei lipämischen und stark getrübten Seren sind Bariumionen für eine ausreichende Klärung des Überstandes erforderlich.

Das Verfahren von Hrrger et al. (11) zur Probengewinnung eignet sich in der hier vorgeschlagenen Modifikation auch für andere enzymatische Methoden, z. B. für die Galaktose- und die Alkoholbestimmung. Dadurch ist es möglich aus einer einzigen Probe von $20 \mu \mathrm{l}$ Blut mehrere Substanzen zu bestimmen.

Die Probenvorbereitung läßt sich mit Hilfe von Reagenzdosierer und Rotationsmischer ebenfalls rationalisieren. Die in Kettenglieder eingesetzten Reaktionsgefäße werden nach der Zentrifugation en bloc in den Analysenautomaten eingesetzt, der ein Aliquot direkt vom Úberstand absaugt. Unter den beschriebenen Bedingungen lassen sich in der Stunde 120 Kapillarblut- und Liquor-, bzw. 60 Urinproben zuverlässig untersuchen: Lediglich bei extremen Konzentrationsdifferenzen in aufeinanderfolgenden Proben sind Verschleppungseffekte zu beachten.

Eine Nichtbeachtung des Verschleppungsfehlers kann, selbst wenn dieser bis zur dreifachen Standardabiweichung der methodischen Streuung (siehe 1. c. (25)) toleriert wird (Abb. 6), in Extremfällen zu einer etheblichen Verfälschung der Ergebnisse führen, obwohl der prozentuale Verschleppungskoeffizient unter $1 \%$ liegt. So 


\section{W Walter de Gruyter Berlin-New York}

Neuerscheinungen

\section{Hilde Götz}

\section{Antigenität von Tumorproteinen}

Oktav. XII, 126 Seiten mit 19 Abbildungen und 6 Tabellen. 1972 Gebunden DM 60,-

Die Monographie versucht, aus der Komplexität der Probleme der Immunonkologie Wesen und klinische Bedeułung der Antigenität von Tumorproteinen darzulegen.

\section{Saturn-Pumpen}

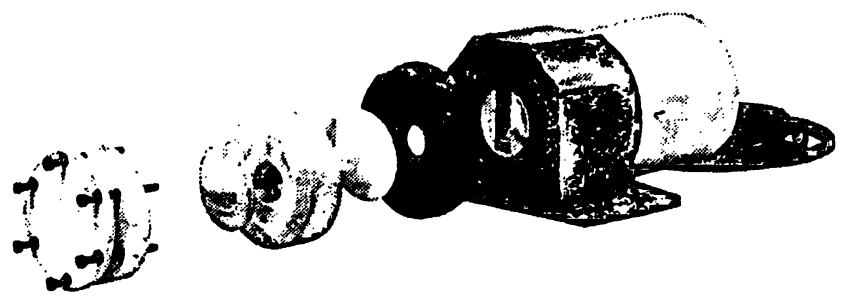

Wir stellen thnen eine gänzlich aus Teflon gefertigte Pumpe vor. Der Name kommt von ihrer Bauart. Das Kernstück ist eine Teflonkugel mit Scheibe. Die Bewegung besteht in einer taumelnden $360^{\circ}$ Drehung der Scheibe innerhalb einer kreisförmigen Kammer. Die Kammer wird durch eine radial angebrachte Scheibe unterteilt. Diese trennt den Ansaugteil vom Austrittsteil und eliminiert so die Notwendigkeit von Ventilen und Kugeln. Die Förderung geschieht vollkommen kontinuierlich. Das Medium kommt nur mit Teflon in Berührung. Die Pumpe ist stets selbstschmierend. Sterilisiert und gereinigt kann sie innerhalb von 5 Minuten werden. Die Pumpen sind leckfrei und frei von einer aus dem Packungsbereich herkommenden Kontamination.

Die Pumpen sind bei Bedarf exegeschützł ausgeführt. Die Leistung kann kontinuierlich geregelt werden. Regelgenauigkeit $\pm 1 \%$, Ansaughöhe (ohne Flüss.) $205 \mathrm{~mm} \mathrm{H} \mathrm{H}_{2} \mathrm{O}$, Ansaughöhe (mit Flüss.) $7300 \mathrm{~mm} \mathrm{H} \mathrm{H}_{2} \mathrm{O}$, max. Druck je nach Modell $0,7-1$ atm.

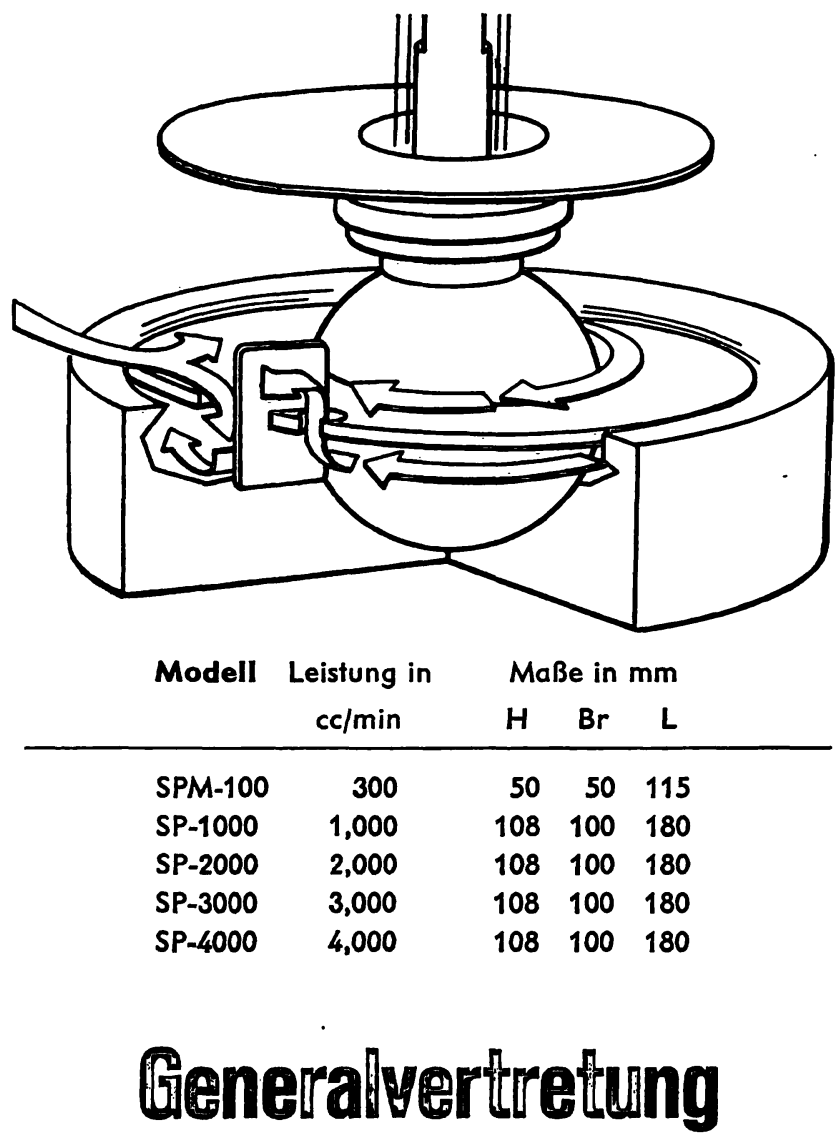

K. E. Kubelik, 75 Karlsruhe 41, Baslertorstr. 64 Tel.: 0721/45552
Oktav. 256 Seiten. Mit 106 Abbildungen. 1973. Gebunden DM 96, -

Das Buch vermittelt Methodik und klinischen Anwendungsbereich der wichtigsten immunologischen Untersuchüngstechniken zur Differenzierung menschlicher Plasmaproteine. Es werden die Immunelektrophorese (Grabar und Williams bzw. Scheidegger) mit reichlichem Anschauungsmaterial und Interpretationshilfen, die zweidimensionale Doppel-Immundiffusion (Ouchterlony) sowie die einfache, radiale Immundiffusion im Agargel (Mancini und Mitarb.) dargelegt. 


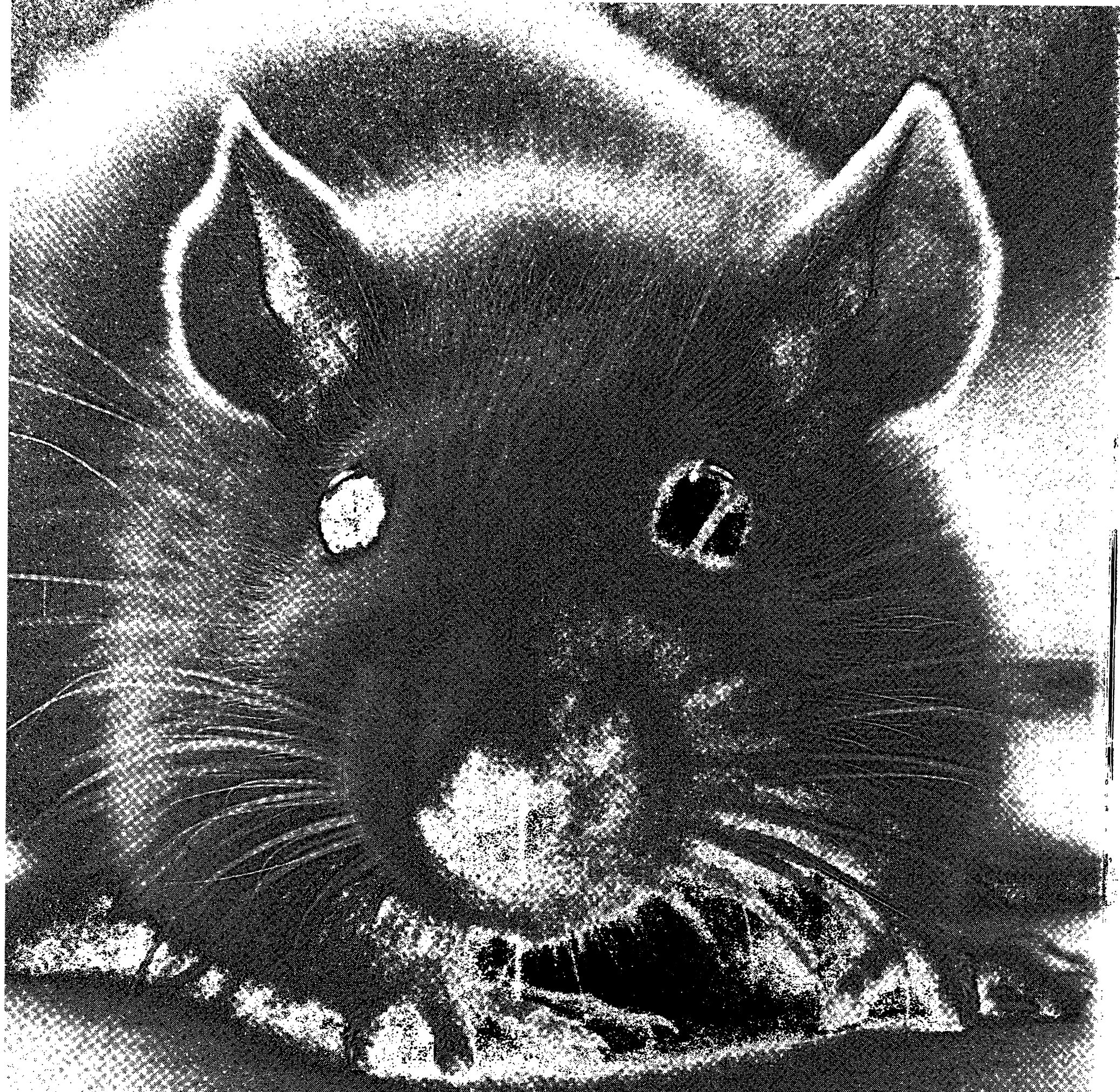


wird eine Konzentration von 0,2 mmol/1, bzw. 1,0 mmol/ 1, die auf eine Probe mit 25 mmol/l folgt, um 100\%, bzw. um $19 \%$ zu hoch gefunden.

Ferner ist bei stark lipämischen Proben in Extremfällen mit einer erheblichen Verfälschung der Ergebnisse zu rechnen. Auch die anderen von uns getesteten Enteiweißungsmittel (Tab. 3) führen bei hohen Triglyceridkonzentrationen nicht zu einer ausreichenden Klärung des Úberstandes. Dieser Fehler läßt sich nur durch Mitführen eines Probenleerwertes vermeiden. Dieses Verfahren erlaubt auch die Verwendung von Perchlorsäure zur Fällung der Proteine. Dabei spart man einen Pipettierschritt, wenn Perchlorsäure vorgelegt wird. Jedoch wird dann die Probendurchsatzgeschwindigkeit reduziert. Außerdem muß auf die automatische Nullpunktskorrektur verzichtet und der Nullabgleich alle 20 Proben überprüft werden.

\section{Anerkennung}

Für die sorgfältige Mitarbeit bei der Durchführung der Versuche danken wir Frau Ciy. Weidemann und Herrn D. Höpfel.

\section{Literatur}

1. Barthelani, W. \& Czok, R. (1962), Klin. Wschr. 40, 585. 2. SCHMIDT, F. H. (1961), Klin. Wschr. 39, 1244. - 3. ReNSCHLER, H. E., WeICKER, H. \& v. BAEYER, H. (1965), Dtsch. med. Wschr. 90, 2349. - 4. Schmrdx, F. H. (1963), in Fortschritte der Diabetesforschung (Hrsg. K. Oberdisse \& K. Jahnke), G. Thieme Verlag, Stuttgart. - 5. HAECKEL, R. (1972), diese Z. 10, 235. 6. Robert, B., de Vaux St. Cyr, Ch., Robert, L. \& Grabar, P. (1959), Clin. Chim. Acta, Amsterdam 4, 828. - 7. Winzler, R. J., Devor, A. W., Mehr, J. W. \& SMYTh, J. M. (1948), J. Clin. Invest. 27, 609. - 8. De Vaux St. Cyr, Cif., Courcon, J. \& Grabar, P. (1958), Bull. Soc. Chim. Biol. 40, 579. - 9. Grabar, P., de Vaux St. Cyr, Ch. \& Cleve, H. (1960), Bull. Soc. Chim. Biol. 42, 853. - 10. Neuberg, C., Strauss, E. \& Lipkin, L. E. (1944), Arch. Biochem. Biophysics 4, 101. - 11. Hilger, P., Henkel, E. \& DelbrücK, A. (1970), diese Z. 8, 579. - 12. Haeckel, R. (1970), diese Z. 8, 480. - 13. EgGstein, M. \& KreUTZ, F. H. (1966), Klin. Wschr. 44, 262. - 14. LeVINE, J. \& ZAK, B. (1964), Clin. Chim. Acta, Amsterdam 10, 381. - 15.
Somogyr, M. (1929), Proc. Soc. exper. Biol. Med. 26, 353. 16. Sомоgyi, M. (1930), J. biol. Chemistry 86, 655. - 17. SoMOGYr, M. (1945), J. biol. Chemistry 160, 69. - 18. KAISER, H. (1965), Z. analyt. Chem. 209, 1. - 19. HAeckel, R. \& HaEckel, H. (1971), diese Z. 9, 278. - 20. DA FonseCa-Wollheim, F. (1971), diese Z. 9, 497. - 21. Netheler, H. (1970), in H. U. Bergmeyer, Methoden der Enzymatischen Analyse, Verlag Chemie, Weinheim, p. 152. - 22. BerGmeYER, H. U. (1970), Methoden der Enzymatischen Analyse, Verlag Chemie, Weinheim, p. 1167. 23. Oucley, J. L., Scathard, G. \& Brown, A. (1947), J. Phys. Coll. Chem. 51, 184. - 24. HJelm, M. (1968), Z. analyt. Chem. 243, 781. - 25. Heackel, R. \& Porth, A. J. (1972), diese $Z$. 10, 91 (1972). - 26. Barthelmai, W. (1969), Monatsschr. Kinderheilkunde 117, 264. - 27. Pfleiderer, G. \& Grein, L. (1957), Biochem. Z. 328, 499. - 28. STORK, H. \& SCMIdT, F. H. (1968), Klin. Wschr. 46, 789. - 29. Da FonseCA-Wollheim, F. (1971), diese Z. 9, 497. - 30. Horvath, A. A. (1946), Analytic. Chem. 18, 229.
Priv. Doz. Dr. R. Haeckel 3 Hannover Karl-Wiechert-Allee 9 